\title{
GLOBALIZAÇÃO ECONÔMICA E IMPASSES ACERCA DA ABORDAGEM \\ INTERDISCIPLINAR NA FLEXIBILIZAÇÃO DO DIREITO DO TRABALHO.
}

\author{
ECONOMIC GLOBALIZATION AND IMPASSES ABOUT THE \\ INTERDISCIPLINARY APPROACH TO FLEXIBILIZING LABOR LAW.
}

ENOQUE FEITOSA SOBREIRA FILHO ${ }^{1}$

SANDRA MARTINI²

ROBERT THOMÉ NETO ${ }^{3}$

\section{RESUMO}

O presente trabalho analisa os impasses acerca da abordagem interdisciplinar entre direito e economia, fruto da globalização econômica, e, como consequência, os reflexos suportados pelo direito do trabalho. Para tanto, a estratégia teórica passa por uma breve análise do fenômeno da globalização econômica bem como pelos entraves na existência de determinada concepção científica interdisciplinar econômico-jurídica. Assim, foi utilizado o método dedutivo-dialético, pelo qual foram aplicados textos constantes de livros, artigos e publicações jurídicas e econômicas, no geral, abordando o referido tema. Ainda, utilizaram-se dados estatísticos com relação à comparação do período anterior e posterior à Reforma Trabalhista, Lei $\mathrm{n}^{\circ} 13.467 / 2017$, no que diz respeito à

\footnotetext{
${ }^{1}$ Coordenador Nacional do GT "Ética e Cidadania" da Associação Nacional de Pós-Graduação em Filosofia, com mandato até 2020. Fez Graduação em Direito na UFPE. Mestrado em Direito pela mesma instituição. É Doutor em Direito pela UFPE e Doutor em Filosofia pela UFPB. Possui estágio Pós-doutoral em Filosofia do direito pela UFSC. Professor Associado na UFPB, lecionando na Graduação e Pós-Graduação em Direito e em Filosofia. Advogado (licenciado). Professor-visitante da Universidade Eduardo Mondlane (Moçambique). Consultor ad hoc da CAPES. É membro de grupos de pesquisa em diversas I.E.S. do país e no exterior. Líder, no âmbito da UFPB, dos Grupos de Pesquisa "Marxismo e Direito" e "Direito, linguagem jurídica e poder" e "Filosofia do direito", que envolve alunos da graduação e da pós-graduação em Direito e em Filosofia. É membro efetivo de várias associações científicas nacionais e internacionais, dentre elas, a Strikes and Social Conflicts International Association - SSCIA; da Associação Nacional de Pós-Graduação em Filosofia - ANPOF; da Associação Brasileira de Filosofia do Direito - ABRAFI, do IVR - Internationale Vereinigung für Rechts und Sozialphilosophie (IVR). É sócio-fundador da Sociedade Ibero-Americana de Retórica. Foi Coordenador do Programa de Pós-Graduação em Ciências Jurídicas da UFPB (Mestrado e Doutorado) durante o quinquênio 2009-2013 e responsável pela área de concentração do Doutorado em 2014-2015. Membro do Conselho Editorial da Revista "Crítica Marxista". Foi proponente, junto a CAPES e, nessa condição, é coordenador do DINTER em Direito entre a UFPB e a UFPI. Coordena o Projeto Internacional CAPES /AULP "O direito entre garantias formais e as demandas por sua concretização" envolvendo a UFPB e a Universidade Nacional Eduardo Mondlane (Moçambique). Tem publicações completas em eventos científicos no exterior, com financiamento AEX/CAPES e fez da parte da equipe responsável pela biblioteca de referência da área de direito da CAPES, sob responsabilidade da UFPB.
} 
empregabilidade brasileira. Os resultados alcançados demonstram que a globalização econômica busca, como fim último, o mercado a serviço do capital. Para tal, adota-se um modelo de sistema cuja eficiência econômica caracteriza-se como valor social supremo, ou seja, no economicismo, no sentido de sobrevalorizar aspectos econômicos em detrimento dos sociais com vistas ao crescimento econômico. Contudo, na prática, observa-se a inexistência de correlação lógica entre flexibilizar a legislação trabalhista e crescimento econômico bem como na manutenção de postos formais de trabalho.

Palavras-chave: Economia; Direito; Globalização; Flexibilização; Trabalho.

\begin{abstract}
This paper analyzes the impasses regarding the interdisciplinary approach between law and economics, as a result of economic globalization, and, as a consequence, the reflections supported by labor law. For that, the theoretical strategy goes through a brief analysis of the phenomenon of economic globalization as well as the obstacles in the existence of a specific interdisciplinary scientific-economic concept. Thus, the deductivedialectic method was used, by which texts from books, articles and legal and economic publications were applied, in general, addressing the referred theme. In addition, statistical data were used in relation to the comparison of the period before and after the Labor Reform, Law No. 13,467 / 2017, with regard to Brazilian employability. The results achieved demonstrate that economic globalization seeks, as the ultimate goal, the market at the service of capital. To this end, a system model is adopted whose economic efficiency is characterized as supreme social value, that is, in economism, in the sense of overvaluing economic aspects to the detriment of social aspects with a view to economic growth. However, in practice, there is no logical correlation between easing labor legislation and economic growth, as well as maintaining formal jobs.
\end{abstract}

Keywords: Economy; Right; Globalization; Flexibility; Job.

\title{
1. INTRODUÇÃO
}

O panorama da globalização proporciona, cada vez mais, condições e estrutura para a consolidação da mundialização econômica do mercado. Esse fenômeno resumese, principalmente, no caminho utilitarista com vistas ao crescimento econômico. Isso, pois, a própria concepção de estado-soberano vem trilhando sua própria erosão, na medida em que não mais possui força e relevância frente ao capital internacional. É neste painel que se observa grande dissensão nas tentativas de se estabelecer determinado, e, deveras necessário, diálogo entre direito e economia. 
Sendo assim, o presente artigo, inicialmente, tratará de maneira sistemática, alguns aspectos no que diz respeito à globalização da economia. Isso se faz necessário para que na sequência se aborde as dificuldades e os motivos pelos quais, ainda hoje, convive-se com o prejuízo oriundo da incomunicabilidade econômico-jurídica.

Para tanto, buscará analisar e estudar os motivos pelos quais direito e economia não possuem metodologia científica calcada na interdisciplinaridade, a fim de superar obstáculo por meio da utilização de linguagem que apresente soluções amparadas tanto pela esfera econômica quanto jurídica, sem que, no entanto, haja sobreposição de uma em desfavor da outra.

É nesse cenário que o direito do trabalho vem a suportar maior prejuízo, ao passo que nenhum outro ramo do direito vive tão próximo das manifestações econômicas como o trabalhista, pois, para todo e qualquer empasse econômico, a primeira solução apresentada se configura na flexibilização da legislação laboral.

Assim, o presente artigo buscará analisar até que ponto a flexibilização dos direitos trabalhistas, fruto da ausência de metodologia interdisciplinar entre direito e economia, proporciona efetivo crescimento econômico.

\section{GLOBALIZAÇÃO ECONÔMICA: BREVES APONTAMENTOS}

De fato, o cenário da globalização proporcionou, e ainda o faz, estrutura e condições para o artifício da consolidação do fenômeno da mundialização econômica do mercado.

Dentre diversos fenômenos que a globalização econômica trouxe, destaca-se, principalmente, o acirramento da concorrência internacional; aumento da acumulação de riqueza em contraponto às desigualdades regionais e sociais; alteração das relações de trabalho; queda de salários; diminuição do intervencionismo estatal em razão de ideologias neoliberais; exclusão social; desemprego estrutural; agravamentos ecológicos... dentre outros.

Em razão disso, pintou-se novo quadro político econômico social, marcado pela implantação das grandes corporações em diversos territórios; avanço da tecnologia nos setores da comunicação e transporte que passam a ocasionar desafios diferentes aos países ditos de primeiro e terceiro mundo. 
Para, além disso, a globalização econômica, principalmente, se pauta num caminho utilitarista para o crescimento econômico. A própria concepção de estadosoberano vem a trilhar sua erosão, na medida em que possui - e se possui - pouco controle de sua respectiva economia nacional, em razão de sua insuficiência frente ao mercado, que agora, passou a estar a serviço do capital globalizado.

A economia nacional, portanto, se desbota em razão do capital internacional, de maneira que esse não possui identidade, nem se baseia em um determinado e delimitado território. Ou seja, os Estados ficam submetidos, involuntariamente, ao jogo da globalização cujas regras os ultrapassam. Nesse jogo, em que a economia se apresenta como tabuleiro, uma das faces do dado é a exigência do afastamento estatal das questões econômicas.

\section{LAW AND ECONOMICS E A INCOMUNICABILIDADE ENTRE DIREITO E ECONOMIA.}

$\mathrm{Na}$ medida em que o globo, cada vez mais, se insere na jogabilidade da globalização econômica a serviço do capital internacional, e, ao passo que se mitiga, na prática, a percepção de autonomia dos Estados-nação, é possível observar grande atrito no embate científico entre direito e economia.

Defender economia e direito como ciências metodologicamente distintas e cientificamente autônomas procria diversos prejuízos que ultrapassam qualquer ordem político-social. Ainda, impossibilita a adoção de uma capacidade analítica voltada a solucionar problemas aos quais se exige - ou pelo menos deveria - a adoção de um caminho comum, abrangido por um objetivo e uma linguagem pautada na esfera interdisciplinar.

Esse isolacionismo do estudo científico também é espólio do processo pelo qual o conhecimento foi - e ainda é - no decorrer de seu desenvolvimento, subdividido em setores de extrema especificidade, os quais passaram a ser incapazes de se comunicar, na medida em que adotaram linguagem e metodologia incompatíveis e incompreensíveis entre si.

Para Teixeira (2004), consequência do isolacionismo científico, tanto a economia quanto o direito colocam e tratam seus respectivos problemas sem atentaremse com o significado ou consequências que possam ter sobre outros domínios, nem, 
tampouco, investigam as possíveis contribuições de outras ciências para suas situações problemas.

Salama (2007, p. 01) sintetiza da seguinte forma:

Enquanto o Direito é exclusivamente verbal, a Economia é também matemática; enquanto o Direito é marcadamente hermenêutico, a Economia é marcadamente empírica; enquanto o Direito aspira ser justo, a Economia aspira ser científica; enquanto a crítica econômica se dá pelo custo, a crítica jurídica se dá pela legalidade. Isso torna o diálogo entre economistas e juristas inevitavelmente turbulento, e geralmente bastante destrutivo.

Segundo Mello (2006) outra dificuldade encontrada na comunicação entre direito e economia diz respeito à formação tradicional do jurista, sendo fortemente influenciada pelo recorte disciplinar da teoria kelseniana, a qual tenta identificar o direito e o que é, propriamente, jurídico, separando-o de outras preocupações não jurídicas, muito embora possam existir relações.

Além disso, o direito estuda fenômenos sociais por meio da linguagem normativa. Portanto, o objeto científico jurídico é a norma, de onde são extraídos preceitos que evocam padrões e condutas, consagram regras e princípios e, ainda, estabelecem valores para os quais os fenômenos jurídicos são estudados.

Por sua vez, dentro da perspectiva econômica existe forte movimento pautado pelo economicismo, ao qual se caracteriza pela tendência em procurar explicar fenômenos e fatos sociais em função dos interesses e necessidades econômicas. Ou seja, quando a própria economia busca explicar o direito sobrevalorizando, contudo, aspectos econômicos.

Assim, Posner (2001) afirma que direito e economia ainda não conseguiram alcançar uma linguagem comum, na medida em que a leitura de textos de economistas e advogados da área indica que cada ciência ainda adota metodologia própria, não integrada e, muitas vezes, completamente distinta. Além disso, enquanto que o direito se isolou das demais ciências, a economia se aproximou das ciências exatas.

Em razão disso, a metodologia utilizada por ambas se opõe. A racionalização da ciência econômica é dedutiva, ou seja, parte de modelos gerais, ao passo que o direito 
investiga sob enfoque indutivo, a partir de situações específicas. Ainda, enquanto que a primeira analisa determinada situação de forma ex-ante, o direito racionaliza ex-post.

Essa diferença metodológica é constatada, especificamente, quando Mello (2006) observa que frequentemente economistas e advogados não conseguem dialogar simplesmente porque estão observando os mesmos problemas a partir de perspectivas distintas, problema que poderia ser suprido a partir da adoção de um plano de análise comum.

Em outras palavras, tanto a ciência econômica quanto a jurídica buscam investigar problemas correlacionados com questões sociais, para tanto, inevitável que ambas possuem, até certo ponto, determinada complementaridade. Entretanto, apenas o reconhecimento desse apêndice não consegue gerar efeitos, efetivamente, suficientes.

Necessário, pois, certa intercomunicação no sentido de se viabilizar que tanto as contribuições de ordem econômica quanto as jurídicas estabeleçam certa coerência e compatibilidade. Talvez seja inviável, na prática, que direito e economia caminhem para mesmas conclusões, mas, ideal seria buscar fins ajustados, intercomunicáveis, sem que, no entanto, um se sobreponha ao outro.

Assim, a análise interdisciplinar deve ir além de uma sobreposição de duas perspectivas sobre um mesmo tema. Ou seja, deve ser fundada num esqueleto metodológico que permita abordar a relação entre ordenamento jurídico normativo e questões socioeconômicas.

Foi nesse contexto de isolacionismo do conhecimento, ao qual o estudo científico foi, no decorrer de seu desenvolvimento, subdivido em setores de extrema especificidade, que, na década de 70 surgiu nos Estados Unidos, movimento pautado em interpretar o direito através de um caminho que se aproximasse do viés econômico.

Isso, porque, as teorias econômicas e jurídicas não conseguiam encontrar suporte e respaldo na realidade fática. Assim, o referido movimento se caracterizou como Law and Economics, ou, Análise Econômica do Direito.

Nesse sentido, Junior (2016) sintetiza que a Análise Econômica do Direito caracteriza-se pelo consequencialíssimo, isto é, acredita-se que as regras pelas quais a sociedade se submete (direito) devem ser elaboradas e aplicadas de acordo com suas consequências no mundo real, e não por um julgamento de valor desprovido de fundamentos empíricos.

Rossetti (1990) sustenta que aquele isolacionismo científico - que caracterizou a maior parte das primeiras investigações econômicas e que se acentuou durante a 
segunda metade do Século XIX - deveria ceder lugar a enfoques interdisciplinares que aproximassem a ciência econômica das outras ciências sociais, devido ao reconhecimento da existência de complexa rede de interdependência que a une com as demais, mais especificamente, com o direito.

Sustentou-se, também, que a fenomenologia estudada pelas ciências sociais era única, no sentido de não existir elementos científicos isolados, ou seja, dissociados dos demais. Portanto, se defendeu que a realidade era uma só, e, uma vez que poderia ser apreciada de vários ângulos para um melhor entendimento, também, poderia ser apreciada em seu conjunto.

Para Pacheco (1994) o movimento caracteriza-se pela aplicação da teoria econômica na explicação do direito, especificamente pela aplicação das categorias e instrumentos teóricos da teoria microeconômica neoclássica, conjuntamente com o ramo da economia do bem-estar na explicação e avaliação das instituições e realidades jurídicas.

Spector (2003, p. 09) ressalta que o paradigma econômico do direito comparte com o utilitarismo a proposição de que o direito pode atribuir benefícios e sanções entre os diferentes indivíduos de modo tal que se maximize o bem-estar geral.

Sendo assim, a análise econômica do direito buscou, no início, afastar-se da percepção positivista, ou seja, caminhou contrário ao desligamento do direito de percepções morais e politicas, da aplicação da norma de maneira neutra, objetiva, lógica e sem qualquer juízo de valor, portanto, sistemática.

Entretanto, o movimento sofreu, e ainda sofre, críticas de percepções econômicas quanto jurídicas, na medida em que na prática, o ideal de interdisciplinaridade não se cristalizou da maneira pela qual se esperava.

McCloskey (1994) aduziu que o movimento da análise econômica do direito, em verdade, representou inicialmente certa evolução jurídica doutrinária, pois saiu da neutralidade positivista ao caminho da ampla análise interdisciplinar entre direito e ciências sociais, especificamente, o estudo das relações entre econômica e direito. Contudo, para a referida professora, atualmente, o movimento se aproxima muito mais do positivismo jurídico, ao passo que busca respostas muito mais albergadas na cientificidade e objetividade do que posturas interdisciplinares que possibilitam interpretações de cunho aberto e social.

Para Coelho (2007) os aplicadores do direito ainda buscam sentido objetivo a suas decisões, e, a economia se apresenta como veículo ideal para tal propósito. 
Pacheco (1994), por sua vez, sustenta que o caráter interdisciplinar, justificativa e fundamento primário da Law and Economics, deve ser reconsiderado, vez que a análise econômica do direito converte a teoria econômica no único conhecimento relevante no estudo jurídico. Ou seja, decisões com base no modelo do sistema de mercado e a eficiência econômica como único valor social. Assim, a economia figura-se como princípio de explicação e justificação última de toda decisão, razão porque esta mediação normativa da economia reduz a análise da questão jurídica a critérios exclusivamente econômicos.

Ainda, Küng (2000), analisa que essa nova economia global de mercado, fruto da análise econômica do direito, exige determinada ética global que: (i) questione o imperialismo econômico que submeta a complexidade das dimensões da sociedade à racionalidade econômica, ou seja, resultados econômicos a objetivos humanos e sociais; (ii) coloque a econômica a serviço das necessidades do homem e não um fim e si; (iii) primazia da ética em face da política e economia, com base no princípio de que, nas palavras do autor:

Os interesses, os imperativos e os cálculos da racionalidade econômica de forma alguma podem atropelar as exigências fundamentais da razão ética baseado no pressuposto de que na economia mundial globalizada não deve imperar um darwinismo social em que sobrevive o mais forte, não podendo sacrificar-se à dignidade humana em nome da liberdade econômica. Para neutralizar a crescente economização da vida é indispensável uma reflexão crítica dos fundamentos que questione as premissas normativas das posições econômicas o que implica em considerar que economia e Estado existem em função do homem, razão porque as instituições estatais e econômicas não só deverão ser expressão do poder, mas deverão responder sempre à dignidade do homem, o que implica na primazia da ética em relação á a economia e à política, que deverão subordinar-se à humanidade do homem, a regras éticas da humanidade (KÜNG, 2000, p. 288 e 289).

Portanto, é certo que a análise econômica do direito representa, como preceito, o princípio da racionalidade econômica. Contudo, não se pode consagrá-lo em patamar axiológico superior, ou seja, como valor absoluto de maneira a se elevar um desfavor do outro, abrindo mão de seu fundamento primário, qual era, caráter interdisciplinar. 
Permanecem, ainda, os questionamentos de Dworkin (1986) sobre a maneira pela qual a análise econômica do direito se configurou, na medida em que até que ponto a riqueza, em detrimento da justiça como ideal metajurídico deve ser o motivador da norma? E, no caso da norma não estimular a produção de riqueza, mas garantir o ideal de justiça deve ser esta derrogada em função da doutrina Law and Economics?

Isso, porque existe forte tendência em se privilegiar a economia em desfavor do direito, principalmente, daqueles situados no domínio social. E, é aqui que se encontra a legislação trabalhista, ao passo que, historicamente, sempre suportou os maiores efeitos da incomunicabilidade interdisciplinar e sobreposição econômica.

\section{A FLEXIBILIZAÇÃO DA LEGISLAÇÃO TRABALHISTA EM FAVOR DO CRESCIMENTO ECONÔMICO.}

Na medida em que, segundo Chaves (2009), a perspectiva globalizante acarreta - no âmbito internacional - novas repercussões com reflexos culturais, políticos, econômicos e sociais, possível dizer que o motor da globalização é o movimento do capital, cujos efeitos implicam em mudanças de paradigmas no que tange ao mercado de trabalho e nas relações de emprego, ou seja, no universo jurídico.

A economia gira em torno da ideia do livre mercado, em que o grande capital (empresas transnacionais) pressionam os governos locais para que se submetam às novas regras de contratação de mão de obra, regras essas entabuladas e determinadas pelo ideal econômico.

Portanto, nenhum outro ramo jurídico vive tão próximo das manifestações econômicas como o direito do trabalho, de maneira que seu conteúdo se tornou, em sua essência, econômico, pois ao se buscar o socialmente desejável, se depara com entraves no economicamente possível.

Para tanto, nesse contexto ideológico neoliberal, sustenta-se que a legislação trabalhista representa um dos cernes das constantes crises econômicas globais, sob a justificativa de que o alto custo da mão-de-obra e o "excesso de direitos" são o que acarretam o elevado índice de desemprego e, portanto, fomentam a informalidade.

Segundo Nascimento (2011) a redução dos níveis de proteção ao trabalhador passou a ser admitida por corrente que acredita ser uma forma de diminuir o desemprego, partindo da premissa de que os empregadores estariam mais dispostos a admitir 
trabalhadores caso não tivessem que suportar altos encargos trabalhistas ou não encontrassem dificuldades para descontratação.

Portanto, a legislação trabalhista se encontra em constante e incansável redefinição, uma vez que para toda e qualquer crise econômica, a primeira solução floresce da "atualização" do direito do trabalho, ou seja, na flexibilização da legislação em serviço dos interesses do mercado globalizado.

Basta, para isso, analisar retroativamente a legislação trabalhista brasileira. A primeira flexibilização ocorreu com a Lei 5.017/1966 que instituiu o fundo de garantia por tempo de serviço, que passou a ser obrigatório a partir da Constituição de $1988 \mathrm{em}$ prejuízo à estabilidade decenal.

Posteriormente, a partir da década de 70, a existência de uma série de alterações, consequência da globalização econômica, e, da redução de custos em razão da competição empresarial e o avanço tecnológico que passou a possibilitar maior produção com menor número de empregados.

Por seguinte, a Lei 6.019/2013 que tratou sobre o trabalho temporário e a Lei 13.429/2017 que, por sua vez, alterou diversos dispositivos da lei anterior, ao passo que possibilitou a terceirização irrestrita da mão de obra, inclusive para as atividades fim do tomador de serviços.

Mais recentemente, a legislação trabalhista foi novamente flexibilizada, e, dessa vez radicalmente, por força da Lei $\mathrm{n}^{\circ}$ 13.467/2017, conhecida como Reforma Trabalhista, na medida em que alterou substancialmente diversos dispositivos da Consolidação das Leis do Trabalho (CLT), consagrando nova percepção para as relações trabalhistas, ao passo que foi implementado o trabalho intermitente; princípio da intervenção mínima passando a prevalecer o acordado sobre o legislado; novas possibilidades de terceirização, dentre outras.

A justificativa da Reforma Trabalhista sustentava pela necessidade de geração de empregos formais e, consequentemente, intensificar o crescimento econômico do país. Nesse sentido, uma vez que a essência da reforma se respaldou no princípio da intervenção mínima, de maneira que o acordado passou a prevalecer sobre o legislado, pode-se concluir que a referida Reforma se pautou, sobretudo, no viés econômico.

Contudo, a última taxa de desemprego divulgada pelo Instituto Brasileiro de Geografia e Estatística (IBGE) foi de 11,8\% no trimestre encerrado em setembro de 2019, com apenas $0,2 \%$ menor que a registrada em novembro de 2017 (12\%). 
Portanto, antes da vigência da Reforma Trabalhista, em 2017, tinha-se uma taxa de desemprego de $12 \%$. Após a vigência de pouco mais de 2 anos da referida reforma, a taxa de desemprego caiu apenas $0,2 \%$, ficando em $11,8 \%$.

A expectativa da Reforma não era apenas a geração de empregos, mas postos de trabalho formais. Nesse sentido, a pesquisa demonstrou que o aumento da população ocupada vem sendo puxado pela informalidade, com empregos precários, sem registro em carteira, sendo que em setembro de 2019 haviam 38,8 milhões de postos de trabalhos informais, ou seja, $41 \%$ de um total de 93,8 milhões.

Por sua vez, o Cadastro Geral de Empregados e Desempregados (CAGED), mostrou o saldo de vagas formais criadas no país, destacando que no período entre novembro de 2017 a setembro de 2019 foram gerados 962 mil postos de trabalho. Número esse bem abaixo da previsão da Reforma em gerar mais de 6 milhões de empregos no país.

Pela análise dos dados acima, é possível estabelecer algumas reflexões. Primeiramente, é certo que não existe nenhuma correlação, pelo menos cristalina, entre flexibilizar a legislação trabalhista e crescimento econômico, na medida em que segundo Maior (2017) as flexibilizações na legislação laboral fundamentam-se em interesses pontuais e imediatos, não sendo fruto de nenhum estudo ou debate aprofundado voltado à melhoria da economia em longo prazo, da reorganização produtiva, e da resolução dos demais problemas que afetam o mundo do trabalho, ou seja, esforça-se para o crescimento econômico (curto prazo e imediato) e abre-se mão do desenvolvimento em longo prazo. Ainda, segundo Dedecca (2014), crescimento econômico não representa, de forma inexorável e na mesma proporção, desenvolvimento social.

José Ajuricaba da Costa e Silva (1996) já dizia que mesmo sob a perspectiva econômica a flexibilização não se sustenta, uma vez que a pobreza abarcada por ela à pessoa do trabalhador em nada ajuda para o crescimento e desenvolvimento econômico.

Percebe-se, ainda, que a flexibilização sempre veio associada ao contexto econômico ao qual está emersa. Flexibilizar as regulamentações das relações de trabalho é, portanto, abrandar ou afrouxar a proteção conferida por ela, de forma a moldá-la aos novos padrões e necessidades exigidas pelo fenômeno da globalização da economia de mercado.

Nesse gancho, também é possível sustentar que não é cristalina a correlação entre flexibilização laboral e recomposição de novos postos de trabalho. Isso, pois, a 
informalidade não é causada pelo rigor da legislação trabalhista, mas em razão de sua própria flexibilização. Nas palavras de Dedecca (2014, p. 17).

Se, no campo do debate político e mesmo acadêmico, o processo de desregulamentação era visto como um instrumento de oxigenação das empresas necessário para relançar o nível de produção e emprego, constata-se que, no movimento real da economia, as empresas têm aproveitado a maior desregulamentação para racionalizar produção e emprego e, portanto, para reforçar a lógica do desemprego.

Em verdade, ocorre o que muitos chamam de "dumping social”, como expressão para aquelas situações em que as empresas transnacionais ameaçam fecharem suas portas em locais com rígida legislação trabalhista, com o intuito de pressionarem no caminho da flexibilização da legislação.

Portanto, uma vez passados mais de dois anos desde a última (e mais severa) flexibilização da legislação laboral brasileira, percebe-se que a criação de novos postos de trabalhos formais não ocorreu, e, consequentemente, o mesmo destino ao crescimento econômico. Certo é que com a flexibilização, criou-se formas de precarização do trabalho em razão da informalidade que passou a atingir a dimensão social dos trabalhadores. A principal consequência reside na desvalorização salarial em que o trabalhador passou a perder sua capacidade de aquisição e consumo, ou seja, em fomentar o próprio mercado.

Com base nesse raciocínio, pode-se especar que a justificativa da necessidade de "atualização ou modernização" das leis trabalhistas com o objetivo de se retomar o crescimento econômico em consequência da criação e manutenção de postos formais de trabalho parece não encontrar sustentação nem fundamentação, inclusive, econômica.

A flexibilização do direito do trabalho se consubstancia como forma de reduzir direitos e garantias trabalhistas, implicando no trabalho fragmentado, precário, subcontrato e a tempo parcial em convívio com o desemprego estrutural.

Ao contrário do que economicamente se sustenta, flexibilização do Direito do Trabalho acarreta um barateamento da mão-de-obra que, por sua vez, passa a aumentar o déficit social distributivo. E, ainda, não se pode olvidar que, em última análise, são as classes operárias os legítimos consumidores finais que movimentam a economia do consumo, sendo essa, sim, indispensável para a sobrevivência do capital. 
Por fim, alerta Castelo (2017) que esse estímulo ao trabalho flexibilizado atende, tão somente, os interesses dos grandes capitais, pois passa a transferir os riscos econômicos e as incertezas aos trabalhadores, e a transferência de renda para as empresas. Portanto, em um país como o Brasil, com extremo déficit social, a legislação trabalhista tem (ou deveria ter) a plenitude de sua razão de ser.

\section{CONSIDERAÇÕES FINAIS}

Parece que um dos muitos efeitos do fenômeno da globalização econômica é o reforço, contínuo, da incomunicabilidade entre direito e economia. Assim, o economicismo passou a ganhar forças no sentido de que a relação da economia com a política é firme na influência sobre o direito.

Esse é o cenário em que o direito do trabalho vem a suportar maior prejuízo, ao passo que nenhum outro ramo do direito vive tão próximo das manifestações econômicas como o trabalhista.

O Direito do Trabalho encontrasse em constante e incansável redefinição, uma vez que para toda e qualquer crise econômica, a primeira solução econômica nasce na "atualização" da legislação trabalhista, ou seja, em sua flexibilização a serviço de interesses do capital.

A última Reforma Trabalhista, Lei n. 13.467/2017, alterou de maneira sem igual à legislação laboral, e, para tanto restou claro que sua principal motivação foi econômica. Novamente, inexistiu relação interdisciplinar econômica-jurídica, na medida em que a economia passou a ser o único valor social pleiteado.

Por meio dos dados apresentados, ficou constatado que, a teoria econômica de que flexibilizar a legislação trabalhista com o intuito de gerar empregos não se sustenta, na medida em que a pobreza abarcada pela flexibilização, abatimento de salários, instabilidades, em nada ajuda o crescimento econômico. E, ainda, de maneira que o consumidor final que movimenta o mercado é, portanto, o próprio trabalhador.

Resta aqui, novamente, a provocação feita por Dworkin (1986) ao se questionar sobre até que ponto a riqueza, em detrimento da justiça como ideal metajurídico deve ser o motivador da norma? De fato, a globalização já escreveu a sua resposta. 


\section{REFERÊNCIAS}

CASTELO, Jorge pinheiro. O direito do trabalho líquido: o negociado sobre o legislado, a terceirização e o contrato de curto prazo na sociedade da modernidade líquida. ABRAT. Belo Horizonte, ano 5, nº 5, 2017, p. 85-116.

CHAVES, Helena Lúcia Augusto. Globalização, ideologia e discurso: uma análise sobre a dimensão ideológica do processo de globalização. Recife. Ed. Universitária da UFPE, 2009.

COELHO, Cristiane de Oliveira. A Análise Econômica do Direito Enquanto Ciência: uma explicação de seu êxito sob a perspectiva da História do Pensamento Econômico. UC Berkeley. Latin American And Caribbean Law and Economics Association Annual Pappers. University of California, 2007. Disponível em: https://escholarship.org/uc/item/47q8s2nd.

DEDECCA, Cláudio Salvadori. Ciclo Temático “Trabalho e Emprego: Novos Desafios". Publicado em 17/02/2014. Disponível em: http://www.iea.usp.br/midiateca/video/videos-2007/recuperacao-do-mercado-detrabalho-brasileiro-ou-estagnacao. Acesso em: 25/11/2019.

DEDECCA, Cláudio Salvadori. Desregulação e desemprego no capitalismo avançado. São Paulo: Fundação SEADE, vol. 10, n. 1, p. 17. Disponível em: http://produtos.seade.gov.br/produtos/spp/v10n01/v10n01_02.pdf. Acesso em: 23/11/2019.

DWORKIN, Ronald. A Matter of Principle. Oxford: Clarendon, 1986.

GICO JR., IVO TEIXEIRA. Introdução à Análise Econômica do Direito. In: Márcia Carla Pereira Ribeiro, Vinicius Klein. (Org.). O que é Análise Econômica do Direito. $2^{\mathrm{a} e d . ~ B e l o ~ H o r i z o n t e: ~ F o ́ r u m, ~ 2016, ~ v . ~ 1, ~ p . ~ 17-26 . ~}$

KÜNG, Hans. Una ética mundial para la economía y la política. México: Fondo de Cultura Económica, 2000.

MELLO, Maria Tereza Leopardi. Direito e Economia - perspectivas da interdisciplinaridade. Diálogos USP. São Paulo, 2006.

NASCIMENTO, Amauri Mascaro. Curso de Direito do Trabalho: história e teoria geral do Direito do Trabalho - relações individuais e coletivas do trabalho. 26. ed. São Paulo: Saraiva, 2011.

PACHECO, Pedro Mercado. El Análisis Económico del Derecho - una reconstrucción teórica. Madrid: Cento de Estudios Constitucionales, 1994. 
POSNER, Richard. Frontiers of Legal Theory. Harward University Press, EUA, 2001.

Reforma Trabalhista Completa 2 anos: veja os principais efeitos. Disponível em:https://g1.globo.com/economia/concursos-e-emprego/noticia/2019/11/11/ reformatrabalhista-completa-2-anos-veja-os-principais-efeitos.ghtml.

ROMAR, Carla Teresa Martins. Direito do Trabalho esquematizado. 2. ed. rev. e atual. São Paulo: Saraiva, 2014.

ROSSETTI, José Paschoal. Introdução à Economia. 14 ed. São Paulo: Atlas, 1990.

SALAMA, Bruno Meyerhof. O que é "Direito e Economia"? Uma introdução à epistemologia da disciplina para o Estudante, o Profissional e o Pesquisador em Direito". Artigo Direito GV (Working Paper), 2007. Disponível em http://www.direitogv.com.br/AppData/Publication/WP3.pdf.

SILVA, José Ajuricaba da Costa e. O direito do trabalho face ao neoliberalismo econômico. Revista do Tribunal Regional do Trabalho da 15a. Região, São Paulo, LTR, 1996.

SPECTOR, Horacio. Justicia y Bienestar: desde uma perspectiva de derecho comparado. Universidad de Alicante, Doxa, nº 26, 2003. ISSN 0214-8876, p. 241-260.

TEIXEIRA (2004). Interdisciplinaridade: problemas e desafios. Revista Brasileira de Pós-Graduação. Numero 1. Julho 2004.

VILLATORE, Marco Antônio César; GUNTHER, Luiz Eduardo. GLOBALIZATION, ECONOMIC CRISIS AND COLLECTIVE BARGAINING IN INTERNATIONAL LABOR LAW. Revista Juridica, [S.1.], v. 51, n. 2, p. 137 - 165, abr. 2018. ISSN 2316$753 X$. Disponível

em: <http://revista.unicuritiba.edu.br/index.php/RevJur/article/view/2803/371371471>.

Acesso em: 20 abr. 2020. doi:http://dx.doi.org/10.21902/revistajur.2316753X.v51i2.2803. 
